Check for updates

Cite this: RSC Adv., 2018, 8, 35367

\title{
Visible light activity of $\mathrm{Bi}_{2} \mathrm{WO}_{6} \mathrm{CTCNQ}$ with core- shell structure in phenol degradation $\uparrow$
}

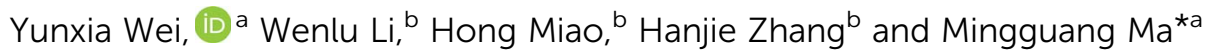 \\ $\mathrm{Bi}_{2} \mathrm{WO}_{6} \mathrm{CTCNQ}$ visible light photocatalyst with a core-shell structure was synthesized by adsorption \\ methods. The core-shell structure results in the fast transfer of photogenerated carriers, reduced carrier \\ recombination and photogenerated holes on the HOMO level of TCNQ can be injected into the VB of \\ $\mathrm{Bi}_{2} \mathrm{WO}_{6}$ under visible light irradiation, resulting in the direct oxidation of organic pollutants. The \\ photocatalytic activity of $\mathrm{Bi}_{2} \mathrm{WO}_{6} \mathrm{QTCNQ}$ was gradually enhanced with an increasing proportion of \\ $T C N Q$. When the mass fraction of TCNQ reaches $0.5 \%$, it exhibits the highest visible light activity. The \\ apparent rate constant $k$ of $\mathrm{Bi}_{2} \mathrm{WO}_{6} \mathrm{QTCNQ}-0.5 \%$ is almost 2.2 times as high as that of pure $\mathrm{Bi}_{2} \mathrm{WO}_{6}$.
}

Received 26th July 2018

Accepted 18th September 2018

DOI: $10.1039 / c 8 \mathrm{ra06304d}$

rsc.li/rsc-advances

range, which is quite promising for expanding the absorption edge of semiconductors.

$\mathrm{Bi}_{2} \mathrm{WO}_{6} @ \mathrm{TCNQ}$ as a higher efficient visible light photo-

Semiconductor-based photocatalysis is considered to be an effective strategy for alleviating energy shortages and environmental pollution, since it is a facile and environmentally friendly way to take advantage of solar energy. ${ }^{1-6}$

In recent years, $\mathrm{Bi}_{2} \mathrm{WO}_{6}$ with the corner-sharing structure of a $\mathrm{WO}_{6}$ octahedron sandwiched between $\left(\mathrm{Bi}_{2} \mathrm{O}_{2}\right) 2 \mathrm{p}$ layers has attracted considerable attention owing to its high visible-light photocatalytic activity. ${ }^{7-10}$ It has also been shown to possess superior photocatalytic activity for wastewater treatments under visible light irradiation. ${ }^{11,12}$ However, similar to other narrowbandgap semiconductor photocatalysts, poor quantum yields caused by the rapid recombination of photogenerated electronhole pairs is still a challenge in enhancing the photocatalytic efficiency of $\mathrm{Bi}_{2} \mathrm{WO}_{6}$ to meet the requirements for practical application. ${ }^{13,14}$ Therefore, the modification of $\mathrm{Bi}_{2} \mathrm{WO}_{6}$ has received considerable attention, and various routes, e.g. substitution, ${ }^{15}$ heterostructure assembly, ${ }^{16,17}$ ions doping, ${ }^{18}$ noble-metal deposition ${ }^{19}$ and carrier coupling, ${ }^{20}$ have been developed to improve the photocatalytic performance of pure $\mathrm{Bi}_{2} \mathrm{WO}_{6}$.

$7,7,8,8$-Tetracyanoquinodimethane (TCNQ) is a neutral organic molecule, whose atoms are all in the same plane, and all the $\mathrm{P}$ electrons of the $\mathrm{C}$ and $\mathrm{N}$ participate in the formation of P-conjugation..$^{21}$ TCNQ can combine with other semiconductors to form charge transfer compounds. ${ }^{22-25}$ These charge transfer compounds can absorb sunlight in almost the whole spectral

aProvincial Key Laboratory of Gansu Higher Education for City Environmental Pollution Control, College of Chemistry and Chemical Engineering, Lanzhou City University, Lanzhou 730070, P. R. China. E-mail:mamg-001@163.com ${ }^{b}$ Department of Chemistry, Tsinghua University, Beijing 100084, P. R. China $\dagger$ Electronic supplementary information (ESI) available. See DOI: $10.1039 / \mathrm{c} 8 \mathrm{ra06304d}$ catalyst with core-shell structure was synthesized via a facile method of adsorption and solution assembly. ${ }^{26-30}$ This simple method could be used as a universal pathway to improve photocatalyst activity and applied in environmental remediation.

\section{Experimental section}

\subsection{Synthesis of photocatalysts}

TCNQ was purchased from Beijing Chemical Reagent Corp, PR China. All other reagents used in this research were of analytical grade and used without further purification.

$\mathrm{Bi}_{2} \mathrm{WO}_{6}$ was prepared according to the method previously described. ${ }^{31} 0.005 \mathrm{mmol} \mathrm{Bi}\left(\mathrm{NO}_{3}\right)_{3} \cdot 5 \mathrm{H}_{2} \mathrm{O}$ and $0.0025 \mathrm{mmol}$ $\mathrm{Na}_{2} \mathrm{WO}_{4} \cdot 2 \mathrm{H}_{2} \mathrm{O}$ were dispersed in $30 \mathrm{~mL}$ deionized water. After stirring for $1 \mathrm{~h}$, the mixed solution was transferred into a $100 \mathrm{~mL}$ PTFE-lined stainless steel autoclave and then heated at $180{ }^{\circ} \mathrm{C}$ for $24 \mathrm{~h}$. Finally, the products were centrifuged and dried in air for $6 \mathrm{~h}$.

The preparation of $\mathrm{Bi}_{2} \mathrm{WO}_{6}$ @ TCNQ photocatalysts was as follows:

$1.25 \mathrm{~g}$ TCNQ was dissolved in $250 \mathrm{~mL}$ tetrahydrofuran (THF) to form a $5 \mathrm{~g} \mathrm{~L}^{-1}$ THF solution of TCNQ. Different volumes of TCNQ solution were measured and diluted to $25 \mathrm{~mL}$ with ethanol. $0.3 \mathrm{~g} \mathrm{Bi}_{2} \mathrm{WO}_{6}$ was added into the above solution after which the beaker was sealed with plastic wrap and placed in an ultrasonic bath for $1 \mathrm{~h}$. The mixture was vigorously stirred in the fume hood until the THF completely evaporated and an opaque powder was obtained. Different mass ratios of $\mathrm{Bi}_{2} \mathrm{WO}_{6} @ \mathrm{TCNQ}$ photocatalysts were prepared in the oven by power evaporation at $100{ }^{\circ} \mathrm{C}$ for $12 \mathrm{~h} . \mathrm{Bi}_{2} \mathrm{WO}_{6}$ and $\mathrm{Bi}_{2} \mathrm{WO}_{6} @ \mathrm{TCNQ}$ electrodes were prepared by the dip coating method: $3 \mathrm{mg}$ of photocatalyst was 
suspended in $1 \mathrm{~mL}$ ethanol to make a slurry, the slurry was then dip-coated onto a $2 \mathrm{~cm} \times 4 \mathrm{~cm}$ indium-tin oxide glass electrode. The electrodes were then exposed to UV light for $12 \mathrm{~h}$ to eliminate ethanol and calcined at $100{ }^{\circ} \mathrm{C}$ for $1 \mathrm{~h}$.

\subsection{Characterization}

The crystallinity of the composites was determined on a Bruker D8 ADVANCE diffractometer under $\mathrm{Cu} \mathrm{K} \alpha$ radiation. The structure and morphologies were examined by field-emission scanning electron microscopy (SEM, LEO-1530).

High-resolution transmission electron microscopy (HRTEM) images were obtained on a JEM 2010F field-emission gun transmission electron microscope at an accelerating voltage of $200 \mathrm{kV}$. Fourier transform infrared (FTIR) spectra were obtained using a Bruker V70FTIR spectrometer. UV-vis diffuse reflectance spectroscopy (UV-DRS) was performed on a Hitachi U-3010 UVvis spectrophotometer with $\mathrm{BaSO}_{4}$ as the reference. Raman spectra were obtained using a Horiba JY HR800 confocal microscope Raman spectrometer under an Ar-ion laser (514 $\mathrm{nm})$. The photocurrent was measured on an electrochemical system (CHI-660B).

\subsection{Photocatalytic evaluation}

The photocatalytic degradation of phenol was conducted under visible light $(>420 \mathrm{~nm})$. The light source was a $500 \mathrm{~W}$ Xe lamp with a $420 \mathrm{~nm}$ cutoff filter, produced by Institute for Electric Light Sources, whose average light intensity was $35 \mathrm{~mW} \mathrm{~cm}{ }^{-2}$. In the photocatalytic experiments, $25 \mathrm{mg}$ of the composite photocatalyst powder was dispersed in an aqueous solution of phenol (50 mL, $5 \mathrm{ppm})$. Before light irradiation, the suspensions were stirred in the dark for $1 \mathrm{~h}$ to ensure absorptiondesorption equilibrium. At intervals of $1 \mathrm{~h}$, aliquots of $2 \mathrm{~mL}$ were withdrawn and centrifuged. The concentration of phenol was analyzed by high-performance liquid chromatography (Shimadzu LC-20AT) with UV detection $(270 \mathrm{~nm})$. A Venusil XBP-C18 (Agela Technologies Inc.) column was used, and the mobile phase consisted of methanol and pure water $(55: 45$ for phenol, v/v) at a flow rate of $1 \mathrm{~mL} \mathrm{~min}^{-1}$.

\subsection{Electrochemical measurement}

To investigate the photoelectrochemical performance of the composites, a standard three-electrode cell was employed, with the composite as the working electrode, a saturated calomel electrode (SCE) as the reference electrode, and a platinum wire as the counter electrode. $\mathrm{Na}_{2} \mathrm{SO}_{4}$ was used as the electrolyte solution. The working electrodes were prepared as follows: The composite $(3 \mathrm{mg}$ ) was suspended in $1 \mathrm{~mL}$ of pure/deionized water under grinding and ultrasound. A slurry was obtained and dip-coated onto an indium tin oxide (ITO) glass electrode.

\section{Results and discussion}

\subsection{Photocatalytic activity}

Fig. 1a and c present the photocatalytic activity of the photocatalysts on the degradation of phenol under visible light $(>420$ $\mathrm{nm}$ ). Dramatically, the apparent rate constant of degradation for 5 ppm phenol initially increased and then decreased with increasing TCNQ content. However, pure TCNQ exhibited no visible light activity. When the mass ratio of TCNQ reached $0.5 \%$, the apparent rate constant of degradation reached a maximum of $0.0286 \mathrm{~h}^{-1}$, nearly 2.2 times that of $\mathrm{Bi}_{2} \mathrm{WO}_{6}$ $\left(0.0136 \mathrm{~h}^{-1}\right)$.

At the same time, HPLC was utilized to investigate the changes of phenol and its degradation intermediates along with irradiation time. Fig. 1b shows the changes of phenol and its degradation intermediates with visible light irradiation. The peak at $1.1 \mathrm{~min}$ was TCNQ, the peaks at 2.0 and $2.2 \mathrm{~min}$ were lower fatty acid, the peak at $3.1 \mathrm{~min}$ was phenol. As the reaction proceeded, the intensity of phenol decreased with the irradiation time whereas the lower fatty acid peaks increased gradually indicating that phenol degraded into small organic molecules.

The stability of $\mathrm{Bi}_{2} \mathrm{WO}_{6}$ @TCNQ was tested by repeated cycling experiments. As shown in Fig. 1d, the photocatalyst exhibited excellent stability. The cyclic photodegradation of 5 ppm phenol was carried out 4 times, for a duration of 6 hours each time. After each cycle, we centrifuged the solution to separate out the photocatalyst; however, because of its nanoscale size and excellent dispersibility in water, there was always a large amount of photocatalyst that did not completely settle, resulting in a loss. However, the subsequent four cycles exhibited similar reaction rates, thus confirming the cycling performance and stability of the photocatalyst for application in photodegradation.

The interfacial charge separation efficiency of photogenerated electrons and holes is a crucial factor for photocatalytic activity. Photocurrents of $\mathrm{Bi}_{2} \mathrm{WO}_{6} @$ TCNQ electrodes were measured to investigate the interfacial charge separation efficiency of photogenerated electrons and holes. It can be seen from Fig. 2a, photocurrents of $\mathrm{Bi}_{2} \mathrm{WO}_{6} @$ TCNQ increased remarkably and then decreased with increasing proportion of TCNQ. Bi ${ }_{2} \mathrm{WO}_{6} @ T C N Q-0.5 \%$ exhibited the highest photocurrent response. The increase of photocurrent indicates that the separation efficiency of the photoinduced electrons and holes was enhanced greatly, which is the reason for the enhanced photocatalytic activity. It also implies that there may be some interaction between $\mathrm{Bi}_{2} \mathrm{WO}_{6}$ and TCNQ. The photocurrent responses decreased gradually when the proportion of TCNQ was over $0.5 \%$, which may be associated with the formation of bulk crystals of TCNQ. The higher the content of TCNQ, the smaller the $\mathrm{Bi}_{2} \mathrm{WO}_{6}$ and TCNQ interaction, resulting in lower catalyst activity (Fig. 1a). Electrochemical impedance spectroscopy (EIS) was performed and the results are shown in Fig. 2b. A smaller arc radius on the EIS Nyquist plot of $\mathrm{Bi}_{2} \mathrm{WO}_{6} @$ TCNQ$0.5 \%$ under visible light irradiation can be observed, suggesting a more effective separation efficiency of the photoinduced electron-hole pairs and a faster charge transfer. The fluorescence emission of $\mathrm{Bi}_{2} \mathrm{WO}_{6} @ T C N Q-0.5 \%$ showed a significant reduction (Fig. 3b). This phenomenon reflected the low recombination probability of photogenerated electrons and holes in $\mathrm{Bi}_{2} \mathrm{WO}_{6} @$ @TCNQ-0.5\%.

The UV-vis DRS spectra of $\mathrm{Bi}_{2} \mathrm{WO}_{6}$ and different mass ratios of the $\mathrm{Bi}_{2} \mathrm{WO}_{6} @ \mathrm{TCNQ}$ photocatalyst are shown in Fig. 2d. As expected, a sharp fundamental absorption edge rises at $477 \mathrm{~nm}$ 

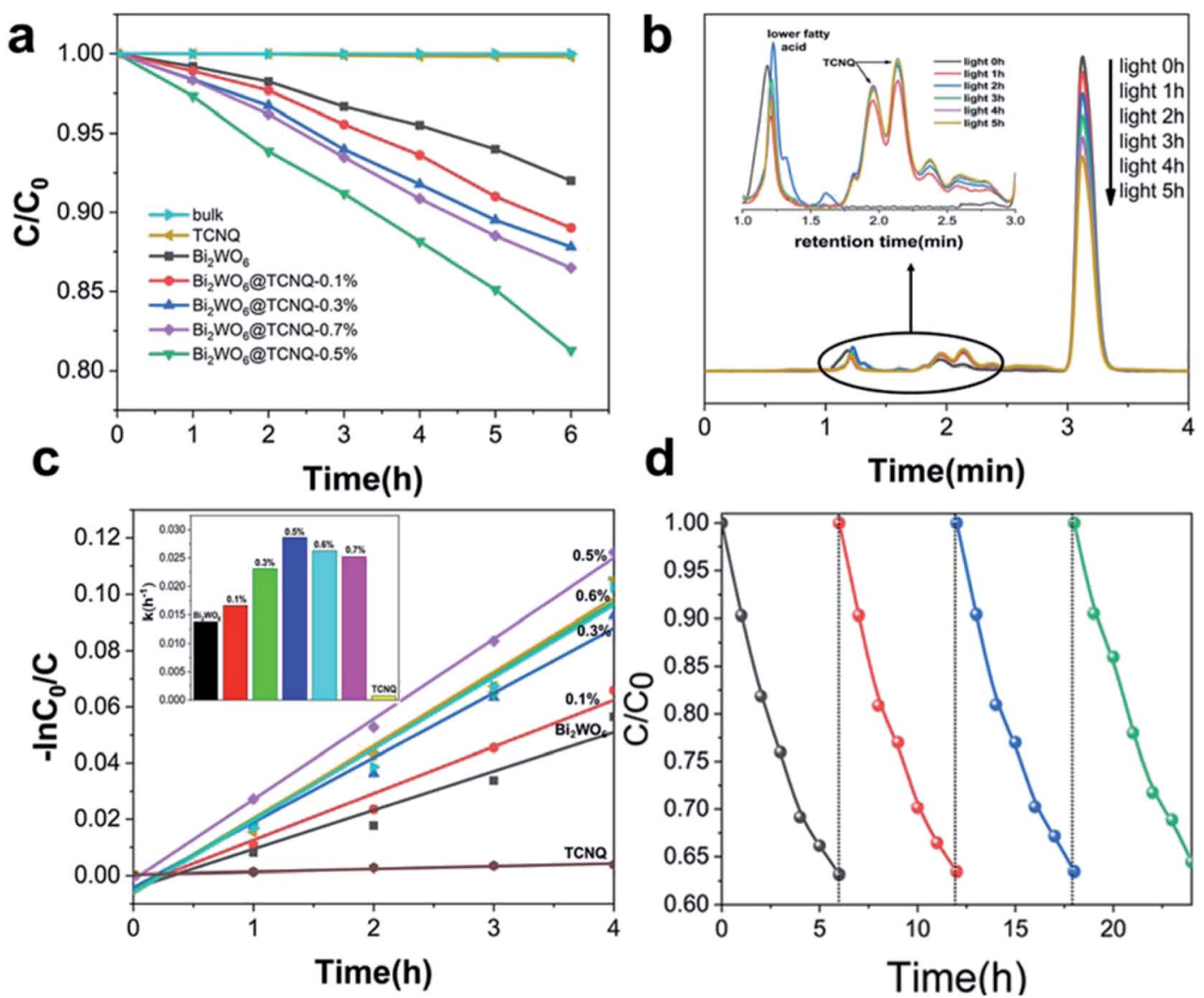

Fig. 1 Comparison of different photocatalysts for photodegradation of phenol (a), HPLC map of initial 5 ppm phenol to the map of phenol after $5 \mathrm{~h}$ of photocatalytic degradation (b). Apparent rate constants $k$ of $\mathrm{Bi}_{2} \mathrm{WO}_{6} @ \mathrm{aTCNQ}$ composite photocatalysts for the degradation of 5 ppm phenol with different TCNQ mass ratios under visible light $(\lambda>420 \mathrm{~nm})(\mathrm{c})$ and cyclic experiments using $\mathrm{Bi}_{2} \mathrm{WO}_{6} @ \mathrm{CTCNQ}-0.5 \%$ for phenol (5 ppm) degradation (d).

for $\mathrm{Bi}_{2} \mathrm{WO}_{6}$, while the absorption edge of $\mathrm{Bi}_{2} \mathrm{WO}_{6} @ \mathrm{TCNQ}$ exhibits an apparent gradual redshift with increasing TCNQ loading. The absorption edge of $\mathrm{Bi}_{2} \mathrm{WO}_{6} @ \mathrm{TCNQ}-0.5 \%$ was at about $521 \mathrm{~nm}$, indicating that absorption edge expanded. The band-edge shift is significant because, in this case, electrons can be stimulated under lower-energy irradiation, allowing for fuller use of the spectrum in comparison to UV photocatalysts. And an apparent red shift for $\mathrm{Bi}_{2} \mathrm{WO}_{6} @ \mathrm{TCNQ}$ composites appears as compared to $\mathrm{Bi}_{2} \mathrm{WO}_{6}$, which may be related to the charge-transfer transition between the $\mathrm{CB}$ or $\mathrm{VB}$ of $\mathrm{Bi}_{2} \mathrm{WO}_{6}$ and TCNQ. ${ }^{32}$ Meanwhile, less photo-corrosion occurs with decreasing excitation energy.

In other words, the faster the charge transfer, the higher the separation efficiency of photoinduced electron-hole pairs and the lower the recombination probability of photo induced carriers in $\mathrm{Bi}_{2} \mathrm{WO}_{6} @ \mathrm{TCNQ}-0.5 \%$. This is also the main reason for the high catalytic activity of $\mathrm{Bi}_{2} \mathrm{WO}_{6} @ T C N Q-0.5 \%$.

\subsection{Core-shell structure of $\mathrm{Bi}_{2} \mathbf{W O}_{6} @ \mathrm{TCNQ}$}

The properties of a material are determined by its structure. Transmission electron microscopy (TEM) analysis shows that the nanosized $\mathrm{Bi}_{2} \mathrm{WO}_{6}$ crystals display mainly a thin sheet shaped morphology and the border lengths of the thin sheets are less than 100 nanometers (Fig. 3a). It can be seen from Fig. 3b, the morphology of $\mathrm{Bi}_{2} \mathrm{WO}_{6} @ \mathrm{TCNQ}$ does not change significantly; with no aggregation phenomenon than that of $\mathrm{Bi}_{2} \mathrm{WO}_{6}$, and TCNQ is exfoliated into sheet structures with rolled edges, the resulting morphology of $\mathrm{Bi}_{2} \mathrm{WO}_{6} @ \mathrm{TCNQ}$ is likely to be of a core-shell structure.

XRD was employed to characterize the crystal phases of $\mathrm{Bi}_{2} \mathrm{WO}_{6}$ and $\mathrm{Bi}_{2} \mathrm{WO}_{6} @ \mathrm{TCNQ}$ composites. As shown in Fig. 3c, all the samples present the typical XRD diffraction character of the orthorhombic $\mathrm{Bi}_{2} \mathrm{WO}_{6}$ phase (JCPDS 39-0256). However, no distinct diffraction peaks attributed to TCNQ can be detected in $\mathrm{Bi}_{2} \mathrm{WO}_{6} @ \mathrm{TCNQ}$ composites, which may be due to the low diffraction intensity, its relatively low dosage amount and good exfoliation of TCNQ in the composite. The results suggest that the incorporation of TCNQ in $\mathrm{Bi}_{2} \mathrm{WO}_{6} @ \mathrm{TCNQ}$ composites does not lead to the development of a new crystal phase or changes in preferential orientations of $\mathrm{Bi}_{2} \mathrm{WO}_{6}$.

The HRTEM image (Fig. 3d) shows clear lattice fringes. The fringes of $d=0.325 \mathrm{~nm}$ match that of the (002) crystallographic plane of $\mathrm{Bi}_{2} \mathrm{WO}_{6}$. The lattice structure of $\mathrm{Bi}_{2} \mathrm{WO}_{6}$ was very orderly and the outer boundary of the as-prepared sample was distinctly different from the $\mathrm{Bi}_{2} \mathrm{WO}_{6}$ core. A distinct core-shell 

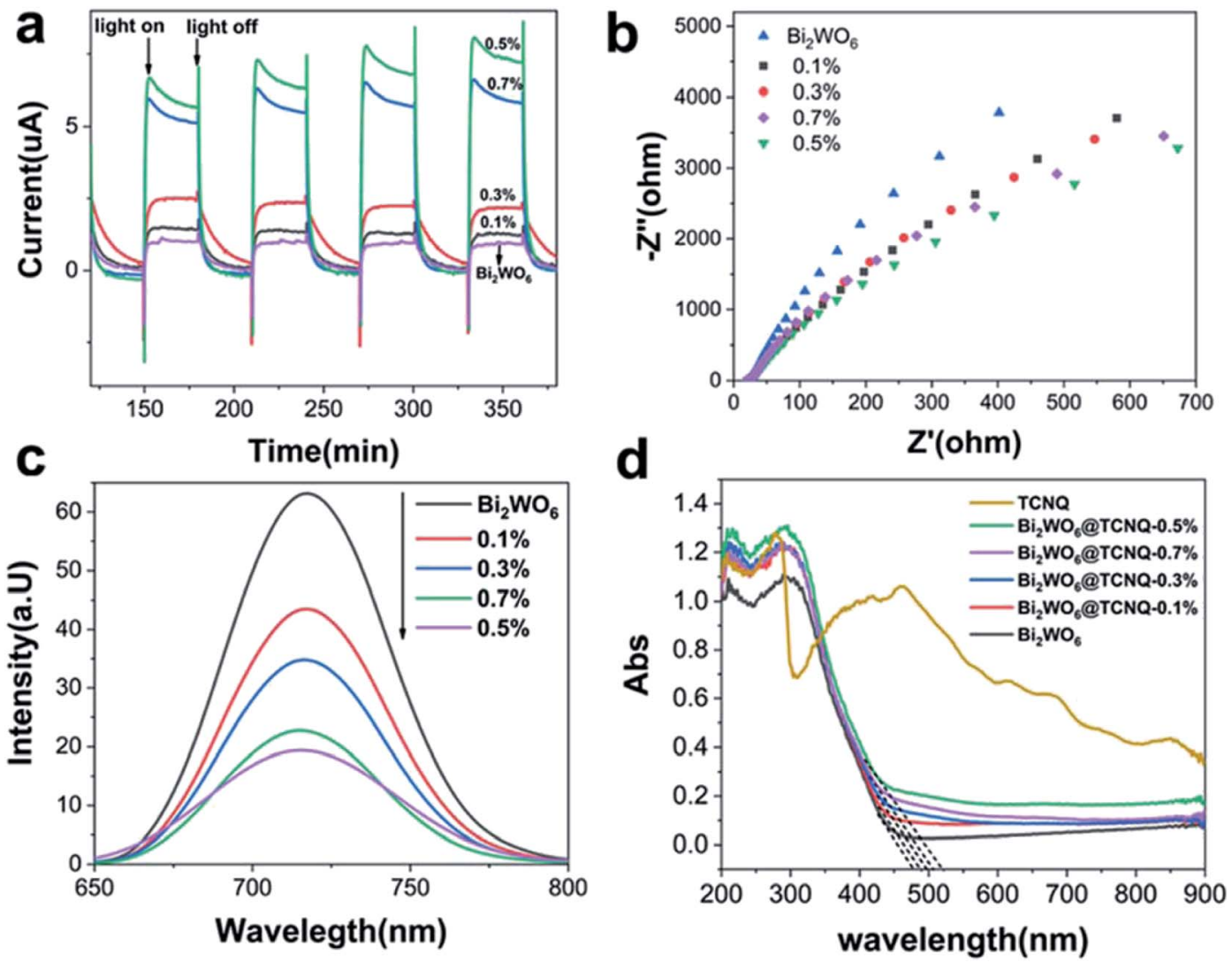

Fig. 2 (a) Photoresponses of $\mathrm{Bi}_{2} \mathrm{WO}_{6}$ and $\mathrm{Bi}_{2} \mathrm{WO}_{6} \mathrm{QTCNQ}$ composites electrodes under the irradiation of visible light $(>420 \mathrm{~nm})\left[\mathrm{Na}_{2} \mathrm{SO}_{4}\right]=$ $0.1 \mathrm{M}$. (b) Electrochemical impedance spectroscopy (EIS) Nyquist plot of $\mathrm{Bi}_{2} \mathrm{WO}_{6}$ and $\mathrm{Bi}_{2} \mathrm{WO}_{6}$ @TCNQ composites upon irradiation ( $\lambda>420 \mathrm{~nm}$ ). (c) Fluorescence spectra of $\mathrm{Bi}_{2} \mathrm{WO}_{6}$ and $\mathrm{Bi}_{2} \mathrm{WO}_{6} \mathrm{QTCNQ}$ composites. (d) UV-DRS spectra of pure $\mathrm{Bi}_{2} \mathrm{WO}_{6}, \mathrm{TCNQ}$ and $\mathrm{Bi}_{2} \mathrm{WO}_{6} \mathrm{QTCNQ}$.

structure was formed and the thickness of the TCNQ layer coated on the $\mathrm{Bi}_{2} \mathrm{WO}_{6} @ \mathrm{TCNQ}-5 \%$ sample was approximately $1 \mathrm{~nm}$, corresponding to two TCNQ layers. ${ }^{33,34}$

In the FT-IR spectrum of TCNQ, the $2207 \mathrm{~cm}^{-1}$ peak was attributable to $\mathrm{C} \equiv \mathrm{N}$ stretching vibration modes. The characteristic vibration of TCNQ at $2207 \mathrm{~cm}^{-1}$ nearly disappeared when TCNQ was loaded onto $\mathrm{Bi}_{2} \mathrm{WO}_{6}$, which indicates that the $\mathrm{C} \equiv \mathrm{N}$ bond strength weakened, suggesting that there was a covalent bond between TCNQ and $\mathrm{Bi}_{2} \mathrm{WO}_{6}$. This interaction is beneficial to the charge migration and the stability of core-shell structure. The characteristic vibration of TCNQ at $2165 \mathrm{~cm}^{-1}$ gradually weakened with increasing TCNQ, which indicates that the bond strength of $\mathrm{W}-\mathrm{O}$ weakened and $\mathrm{Bi}_{2} \mathrm{WO}_{6}$ combined with TCNQ by chemical bonding rather than mechanical mixing.

Fig. $4 \mathrm{~b}$ shows the Raman spectra of $\mathrm{Bi}_{2} \mathrm{WO}_{6}$ and various $\mathrm{Bi}_{2} \mathrm{WO}_{6} @ T C N Q$ photocatalysts. The Raman shifts at 333, 600 and $708 \mathrm{~cm}^{-1}$ arise from the lattice vibrational peaks of TCNQ crystal, corresponding to the Ag (9) mode, Ag (8) mode and Ag (7) mode of TCNQ crystal, ${ }^{34}$ respectively. The peak at $143 \mathrm{~cm}^{-1}$ was attributable to the lattice vibrational peaks of $\mathrm{Bi}_{2} \mathrm{WO}_{6}$ crystal, which move to a lower wavenumber with increasing TCNQ. The red shift of this band indicates that the bond strengths of $\mathrm{W}-\mathrm{O}$ weakened, suggesting that there is a covalent bond between the conjugated bond of TCNQ and
$\mathrm{Bi}_{2} \mathrm{WO}_{6}{ }^{35}$ The interaction is concerned with the charge transfer absorption peaks and the red shift of the absorption sideband shown in Fig. 2 d.

\subsection{Mechanism}

To reveal the photocatalytic mechanism, the main oxidative species in the photocatalytic process are detected through the trapping experiments of radicals using $t \mathrm{BuOH}^{36}$ as a hydroxyl radical scavenger, and formic acid ${ }^{37}$ as holes radical scavenger. As shown in Fig. 5a, the photocatalytic activity of $\mathrm{Bi}_{2} \mathrm{WO}_{6}$ @TCNQ under visible light irradiation significantly decreases with the addition of a holes scavenger (formic acid) and reduces slightly with the addition of a hydroxyl radical scavenger $(t \mathrm{BuOH})$, indicating that holes radicals are the main oxidative species rather than hydroxyl radicals. On the basis of the above experimental results, a possible mechanism for the degradation of phenol under visible light irradiation is proposed, as shown in Fig. 5b. Photogenerated electrons and holes are generated on the HOMO and LUMO of TCNQ, at the same time they are generated on the $\mathrm{VB}$ and $\mathrm{CB}$ of $\mathrm{Bi}_{2} \mathrm{WO}_{6}$ when irradiated by visible light. As the HOMO orbit of TCNQ is lower than the VB of $\mathrm{Bi}_{2} \mathrm{WO}_{6} \cdot{ }^{38}$ photogenerated holes on the HOMO of TCNQ can be injected easily into the $\mathrm{VB}$ of $\mathrm{Bi}_{2} \mathrm{WO}_{6}$. The holes injected into the $\mathrm{VB}$ of $\mathrm{Bi}_{2} \mathrm{WO}_{6}$ can directly oxidize the organic pollutant, which contributes to the drastic visible light activity of 


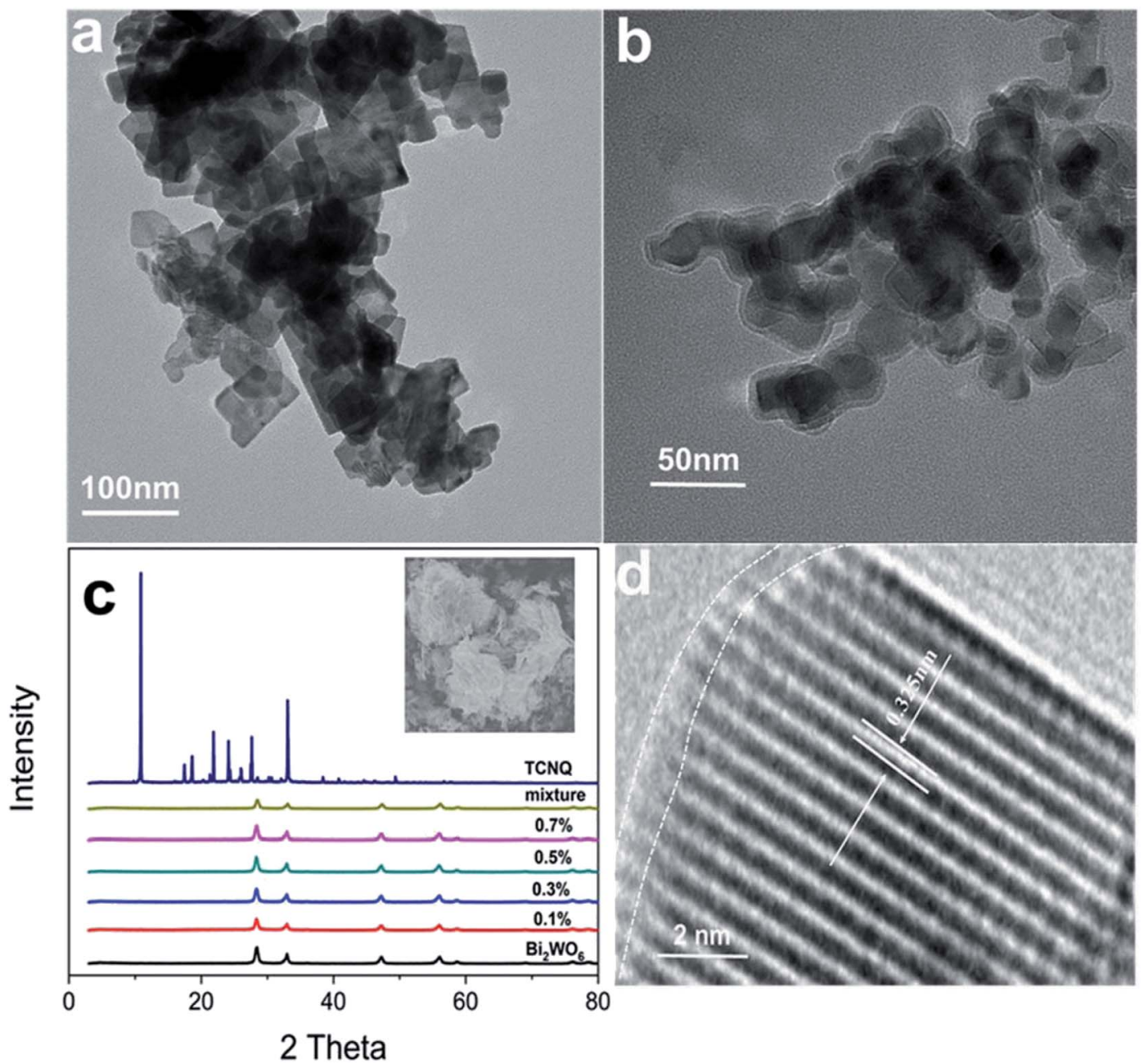

Fig. 3 TEM images of (a) $\mathrm{Bi}_{2} \mathrm{WO}_{6}$ and (b) $\mathrm{Bi}_{2} \mathrm{WO}_{6}$ (aTCNQ-0.5\%; (c) XRD patterns of $\mathrm{Bi}_{2} \mathrm{WO}_{6}$ and $\mathrm{Bi}_{2} \mathrm{WO}_{6}$ (aTCNQ; (d) $\mathrm{HRTEM}$ images of $\mathrm{Bi}_{2}-$ $\mathrm{WO}_{6} @ \mathrm{aTCNQ}-0.5 \%$.

$\mathrm{Bi}_{2} \mathrm{WO}_{6} @ \mathrm{TCNQ}$ photocatalyst in phenol degradation. As the CB position of $\mathrm{Bi}_{2} \mathrm{WO}_{6}$ is higher than the lowest unoccupied molecular orbital (LUMO) of TCNQ, ${ }^{38}$ photogenerated electrons on the $\mathrm{CB}$ of $\mathrm{Bi}_{2} \mathrm{WO}_{6}$ can be easily injected to the LUMO orbit of
TCNQ. However, the LUMO orbit of TCNQ is too low for electrons to easily combine with $\mathrm{O}_{2}$, which prevents the formation of hydroxyl radicals.
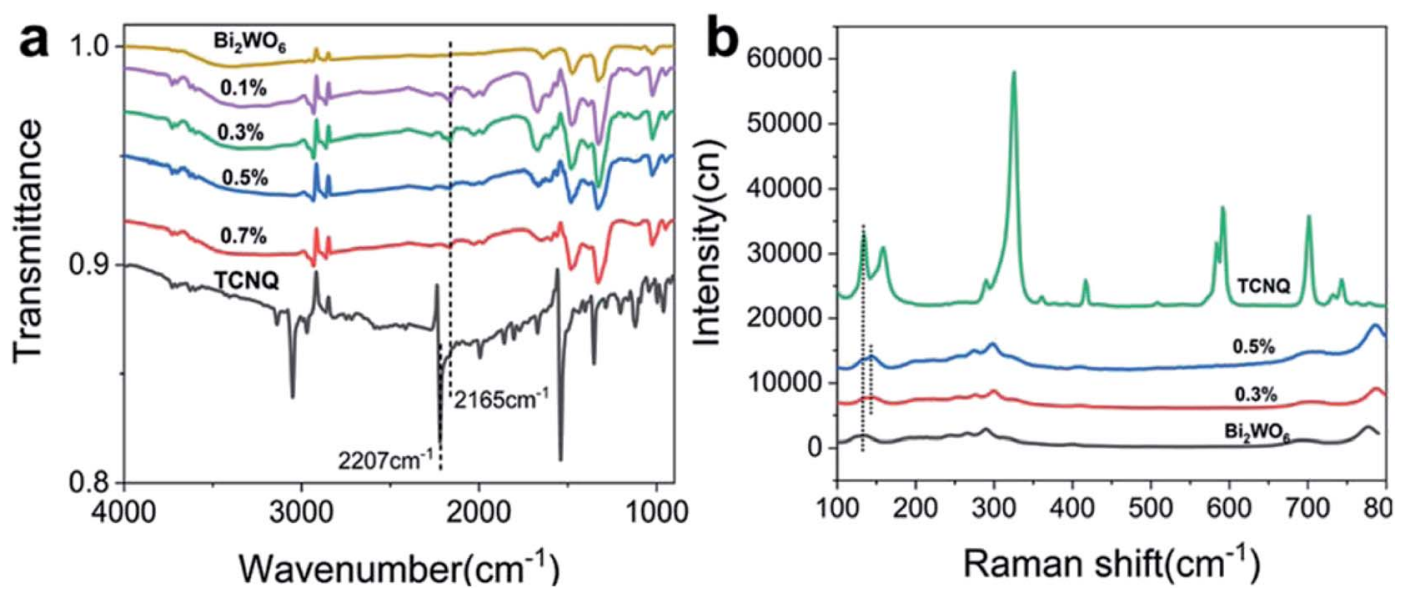

Fig. 4 (a) FTIR and (b) Raman spectra of $\mathrm{Bi}_{2} \mathrm{WO}_{6}$ and $\mathrm{Bi}_{2} \mathrm{WO}_{6} @ \mathrm{TCNQ}$ photocatalysts. 

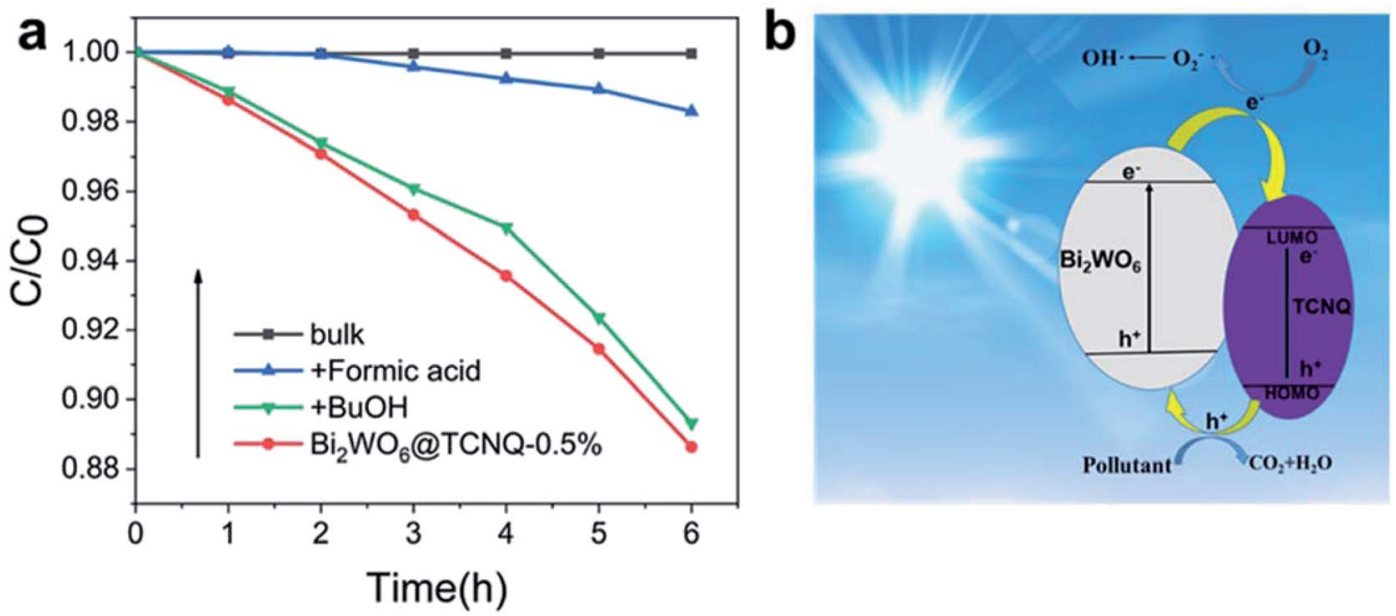

Fig. 5 The plots of photogenerated carriers trapping in the system of photodegradation of phenol by (a) $\mathrm{Bi}_{2} \mathrm{WO}_{6} @ \mathrm{aTCNQ}-0.5 \%$ under visible light (b) mechanism plots under visible light.

\section{Conclusion}

$\mathrm{Bi}_{2} \mathrm{WO}_{6} @ \mathrm{TCNQ}$ photocatalyst with a core-shell structure was synthesized. This structure enhances the photocatalytic properties of the materials. When the mass ratio of TCNQ reached $0.5 \%$, the apparent rate constant of degradation was nearly 2.2 times that of $\mathrm{Bi}_{2} \mathrm{WO}_{6}$. Its visible light activity comes from the injection of photogenerated holes on the HOMO of TCNQ into the $\mathrm{VB}$ of $\mathrm{Bi}_{2} \mathrm{WO}_{6}$ under visible light irradiation. The holes injected into the $\mathrm{VB}$ of $\mathrm{Bi}_{2} \mathrm{WO}_{6}$ could directly oxidize the organic pollutant.

\section{Conflicts of interest}

There are no conflicts to declare.

\section{Acknowledgements}

This study was partly supported by Chinese National Science Foundation (21621003), Natural Science Foundation of Gansu province (18JR3RA219) and Lanzhou City University key discipline "Analysis and Treatment of Regional Typical Environmental Pollutants".

\section{References}

1 Y. Li, W. Q. Cui, L. Liu, R. L. Zong, W. Q. Yao, Y. H. Liang and Y. F. Zhu, Removal of $\mathrm{Cr}(\mathrm{VI})$ by $3 \mathrm{D} \mathrm{TiO}_{2}$-graphene hydrogel via adsorption enriched with photocatalytic reduction, Appl. Catal., B, 2016, 199, 412-423.

2 F. Y. Chen, W. J. An, L. Liu, Y. H. Liang and W. Q. Cui, Highly efficient removal of bisphenol A by a three-dimensional graphene hydrogel-AgBr@rGO exhibiting adsorption/ photocatalysis synergy, Appl. Catal., B, 2017, 217, 65-80.

3 X. Wang, Y. H. Liang, W. J. An, J. S. Hu, Y. F. Zhu and W. Q. Cui, Removal of chromium (VI) by a selfregenerating and metal free $g-\mathrm{C}_{3} \mathrm{~N}_{4}$ /graphene hydrogel system via the synergy of adsorption and photo-catalysis under visible light, Appl. Catal., B, 2017, 219, 53-62.

4 L. Liu, L. Ding, Y. G. Liu, W. J. An, S. L. Lin, Y. H. Liang and W. Q. Cui, A stable $\mathrm{Ag}_{3} \mathrm{PO}_{4} @ P A N I$ core@shell hybrid: enrichment photocatalytic degradation with $\pi-\pi$ conjugation, Appl. Catal., B, 2017, 201, 92-104.

5 W. Q. Cui, J. He, H. Wang, J. S. Hu, L. Liu and Y. H. Liang, Polyaniline hybridization promotes photo-electro-catalytic removal of organic contaminants over 3D network structure of rGH-PANI/TiO ${ }_{2}$ hydrogel, Appl. Catal., B, 2018, 232, 232-245.

6 Y. Zhang, W. Q. Cui, W. J. An, L. Liu, Y. H. Liang and Y. F. Zhu, Combination of photoelectrocatalysis and adsorption for removal of bisphenol A over $\mathrm{TiO}_{2}$-graphene hydrogel with 3D network structure, Appl. Catal., B, 2018, 221, 36-46.

7 N. Zhang, R. Ciriminna, M. Pagliaro and Y. J. Xu, Nanochemistry-derived $\mathrm{Bi}_{2} \mathrm{WO}_{6}$ nanostructures: towards production of sustainable chemicals and fuels induced by visible light, Chem. Soc. Rev., 2014, 43, 5276-5287.

8 Y. G. Zhou, Y. F. Zhang, M. S. Lin, J. L. Long, Z. Z. Zhang, H. X. Lin, J. C. S. Wu and X. X. Wang, Monolayered $\mathrm{Bi}_{2} \mathrm{WO}_{6}$ nanosheets mimicking heterojunction interface with open surfaces for photocatalysis, Nat. Commun., 2015, 6, 1-8.

9 L. Tang, J. J. Wang, G. M. Zeng, Y. N. Liu, Y. C. Deng, Y. Y. Zhou, J. Tang, J. J. Wang and Z. Guo, Enhanced photocatalytic degradation of norflox J. J. cin in aqueous $\mathrm{Bi}_{2} \mathrm{WO}_{6}$ dispersions containing nonionic surfactant under visible light irradiation, J. Hazard. Mater., 2016, 306, 295304.

10 X. Y. Kong, Y. Y. Choo, S. P. Chai, A. K. Soh and A. R. Mohamed, Oxygen vacancy induced $\mathrm{Bi}_{2} \mathrm{WO}_{6}$ for the realization of photocatalytic $\mathrm{CO}_{2}$ reduction over the full solar spectrum: from the UV to the NIR region, Chem. Commun., 2016, 52, 14242-14245.

11 Y. H. B. Liao, J. X. Wang, J. S. Lin, W. H. Chung, W. Y. Lin and C. C. Chen, Synthesis, photocatalytic activities and 
degradation mechanism of $\mathrm{Bi}_{2} \mathrm{WO}_{6}$ toward crystal violet dye, Catal. Today, 2011, 174, 148-159.

12 S. Y. Dong, X. H. Ding, T. Guo, X. P. Yue, X. Han and J. H. Sun, Self-assembled hollow sphere shaped $\mathrm{Bi}_{2} \mathrm{WO}_{6} /$ RGO composites for efficient sunlight-driven photocatalytic degradation of organic pollutants, Chem. Eng. J., 2017, 316, 778-789.

13 L. S. Zhang, W. Z. Wang, L. Zhou and H. L. Xu, $\mathrm{Bi}_{2} \mathrm{WO}_{6}$ nanoand microstructures: shape control and associated visiblelight-driven photocatalytic activities, Small, 2007, 3, 16181625.

14 Z. J. Zhang, W. Z. Wang, L. Wang and S. M. Sun, Enhancement of visible-light photocatalysis by coupling with narrow-band-gap semiconductor: a case study on $\mathrm{Bi}_{2} \mathrm{~S}_{3} / \mathrm{Bi}_{2} \mathrm{WO}_{6}$, ACS Appl. Mater. Interfaces, 2012, 4, 593-597.

15 N. Tian, Y. H. Zhang, H. W. Huang, Y. He and Y. X. Guo, Influences of Gd substitution on the crystal structure and visible-light-driven photocatalytic performance of $\mathrm{Bi}_{2} \mathrm{WO}_{6}$, J. Phys. Chem. C, 2014, 118, 15640-15648.

16 Y. H. Xiang, P. Ju, Y. Wang, Y. Sun, D. Zhang and J. Q. Yu, Chemical etching preparation of the $\mathrm{Bi}_{2} \mathrm{WO}_{6} / \mathrm{BiOI} p-n$ heterojunction with enhanced photocatalytic antifouling activity under visible light irradiation, Chem. Eng. J., 2016, 288, 264-275.

17 J. Tian, Y. H. Sang, G. W. Yu, H. D. Jiang, X. N. Mu and H. Liu, A $\mathrm{Bi}_{2} \mathrm{WO}_{6}$-based hybrid photocatalyst with broad spectrum photocatalytic properties under UV, visible, and near-infrared irradiation, Adv. Mater., 2013, 25, 5075-5080.

18 G. Tan, J. Huang, L. Zhang, H. Ren and A. Xia, An enhanced visible-light-driven photocatalyst: conduction band control of $\mathrm{Bi}_{2} \mathrm{WO}_{6}$ crystallites by $\mathrm{Cu}$ ion modification, Ceram. Int., 2014, 40, 11671-11679.

19 Q. S. Wu, Y. Cui, L. M. Yang, G. Y. Zhang and D. Z. Gao, Facile in situ photocatalysis of $\mathrm{Ag} / \mathrm{Bi}_{2} \mathrm{WO}_{6}$ heterostructure with obviously enhanced performance, Sep. Purif. Technol., 2015, 142, 168-175.

20 Y. J. Wang, X. J. Bai, C. S. Pan, J. He and Y. F. Zhu, Enhancement of photocatalytic activity of $\mathrm{Bi}_{2} \mathrm{WO}_{6}$ hybridized with graphite-like $\mathrm{C}_{3} \mathrm{~N}_{4}$, J. Mater. Chem., 2012, 22, 11568-11573.

21 i. I. Garcia-Yoldi, J. S. Miller and J. J. Novoa, Theoretical study of the electronic structure of [tetrathiafulvalene $]_{2}{ }^{2+}$ dimers and their Long, intradimer multicenter bonding in solution and the solid state, J. Phys. Chem. A, 2008, 113, 484-492.

22 J. Ferraris, D. O. Cowan, V. Walatka and J. H. Perlstein, Electron Transfer in a New Highly Conducting DonorAcceptor Complex, J. Am. Chem. Soc., 1973, 95, 948-949.

23 Y. Washino, K. Murata, M. Ashizawa, S. Kawauchi and T. Michinobu, Creation of persistent charge-transfer interactions in TCNQ polyester, Polym. J., 2011, 43, 364-369.

$24 \mathrm{~N}$. Yoshioka, H. Nishide, K. Inagaki, K. Inagaki and E. Tsuchida, Electrical conductive and magnetic properties of conjugated tetrathiolate nickel polymers, Polym. Bull., 1990, 23, 631-636.

25 S. Inagi, K. Naka and Y. Chujo, Functional polymers based on electron-donating TTF and derivatives, J. Mater. Chem., 2007, 17, 4122-4135.

26 B. J. Li and H. Q. Cao, ZnO@graphene composite with enhanced performance for the removal of dye from water, J. Mater. Chem., 2011, 21, 3346-3349.

27 T. G. Xu, L. W. Zhang, H. Y. Cheng and Y. F. Zhu, Significantly enhanced photocatalytic performance of $\mathrm{ZnO}$ via graphene hybridization and the mechanism study, Appl. Catal., B, 2011, 101, 382-387.

28 Y. Yang, L. L. Ren, C. Zhang, S. Huang and T. X. Liu, Facile Fabrication of Functionalized Graphene Sheets (FGS)/ZnO Nanocomposites with Photocatalytic Property, ACS Appl. Mater. Interfaces, 2011, 3, 2779-2785.

29 X. J. Bai, L. Wang, R. L. Zong, Y. H. Lv, Y. Q. Sun and Y. F. Zhu, Performance Enhancement of ZnO Photocatalyst via Synergic Effect of Surface Oxygen Defect and Graphene Hybridization, Langmuir, 2013, 29, 3097-3105.

30 Y. J. Wang, R. Shi, J. Lin and Y. F. Zhu, Enhancement of photocurrent and photocatalytic activity of $\mathrm{ZnO}$ hybridized with graphite-like $\mathrm{C}_{3} \mathrm{~N}_{4}$, Energy Environ. Sci., 2011, 4, 29222929.

$31 \mathrm{C}$. Zhang and Y. F. Zhu, Synthesis of square $\mathrm{Bi}_{2} \mathrm{WO}_{6}$ nanoplates as high-activity visible-light-driven photocatalysts, Chem. Mater., 2005, 17, 3537-3545.

32 J. Yang, X. Wang, X. Zhao, J. Dai and S. Mo, Synthesis of uniform $\mathrm{Bi}_{2} \mathrm{WO}_{6}$-reduced graphene oxide nanocomposites with significantly enhanced photocatalytic reduction activity, J. Phys. Chem. C, 2015, 119, 3068-3078.

33 R. E. Long, R. A. Sparks and K. N. Trueblood, The crystal and molecular structure of 7,7,8,8-tetracyanoquinodimethane, Acta Crystallogr., 1965, 18, 932-939.

34 Z. P. Hu, Z. X. Shen, L. Qin, S. H. Tang, M. H. Kuok, G. Q. Xu, K. F. Mok and H. H. Huang, High pressure Raman studies of 7,7,8,8-tetracyanoquinodimethane (TCNQ) and CuTCNQ, $J$. Mol. Struct., 1995, 356, 163-168.

35 Y. J. Wang, R. Shi, J. Lin and Y. F. Zhu, Significant photocatalytic enhancement in methylene blue degradation of $\mathrm{TiO}_{2}$ photocatalysts via graphene-like carbon in situ hybridization, Appl. Catal., B, 2010, 100, 179-183.

36 H. J. Lee and W. Y. Choi, Photocatalytic Oxidation of Arsenite in $\mathrm{TiO}_{2}$ Suspension: Kinetics and Mechanisms, Environ. Sci. Technol., 2002, 36, 3872-3878.

37 T. Tan, D. Beydoun and R. Amal, Effects of organic hole scavengers on the photocatalytic reduction of selenium anions, J. Photochem. Photobiol., A, 2003, 159, 273-280.

38 N. Martín, J. L. Segura and C. Seoane, Design and synthesis of TCNQ and DCNQI type electron acceptor molecules as precursors for 'organic metals', J. Mater. Chem., 1997, 7, 1661-1676. 